\title{
Kinetic studies of adsorption of Fe(III) from aqueous solution by untreated and alkali-treated rice straw
}

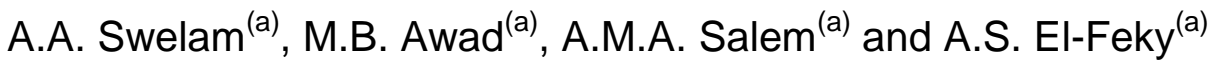 \\ ${ }^{a}$ Chemistry Department, Faculty of Science, Al-azhar University,11884 Cairo, Egypt \\ Corresponding author:ahmed.samer8787@yahoo.com(A.S. El-Feky)
}

\begin{abstract}
Modifications of rice straws surfaces by sodium hydroxide $(\mathrm{NaOH})$ were carried out in order to study the effects of this on the surface functional groups properties. Comparison was made between untreated and alkali-treated rice straws on the removal of $\mathrm{Fe}$ (III) from aqueous solution. In this study, four characterizations of raw rice straw have been conducted. The morphological characteristics by Scanning Electron Microscope (SEM), Energy Dispersive X-ray Analysis (EDXA)the functional group present in the rice straw by Fourier Transform Infrared (FTIR) spectroscopy and the X-ray Diffraction (XRD). The result of Scanning Electron Microscopy (SEM) also shows that rice straw is a porous material. Rice straw contains on $-\mathrm{OH}$ functional group that can bind with metal ions. To be able to enhance the sorption capacity of rice straw in metals, removing from waste water, alkali treatment should be done. This shows that rice straw can be used as adsorbent for ferric ions removing from wastewater. The effect of $\mathrm{pH}$, sorption kinetics and isotherms were studied in batch experiments. The good correlation coefficient was obtained from pseudo second-order kinetic model, which agreed with conception as the rate-limiting mechanism. Sorption isotherm test showed that equilibrium sorption data were better represented by Temkin model. The highly efficient, low cost and the rapid uptake of Fe(III) by untreated (RS) in comparison with alkali-treated (MRS) rice straws, indicated that it could be an excellent alternative for the removal of ferric ions by sorption process.
\end{abstract}

\section{Key words}

Rice straw; Adsorption;Ferric; Kinetic; Thermodynamic

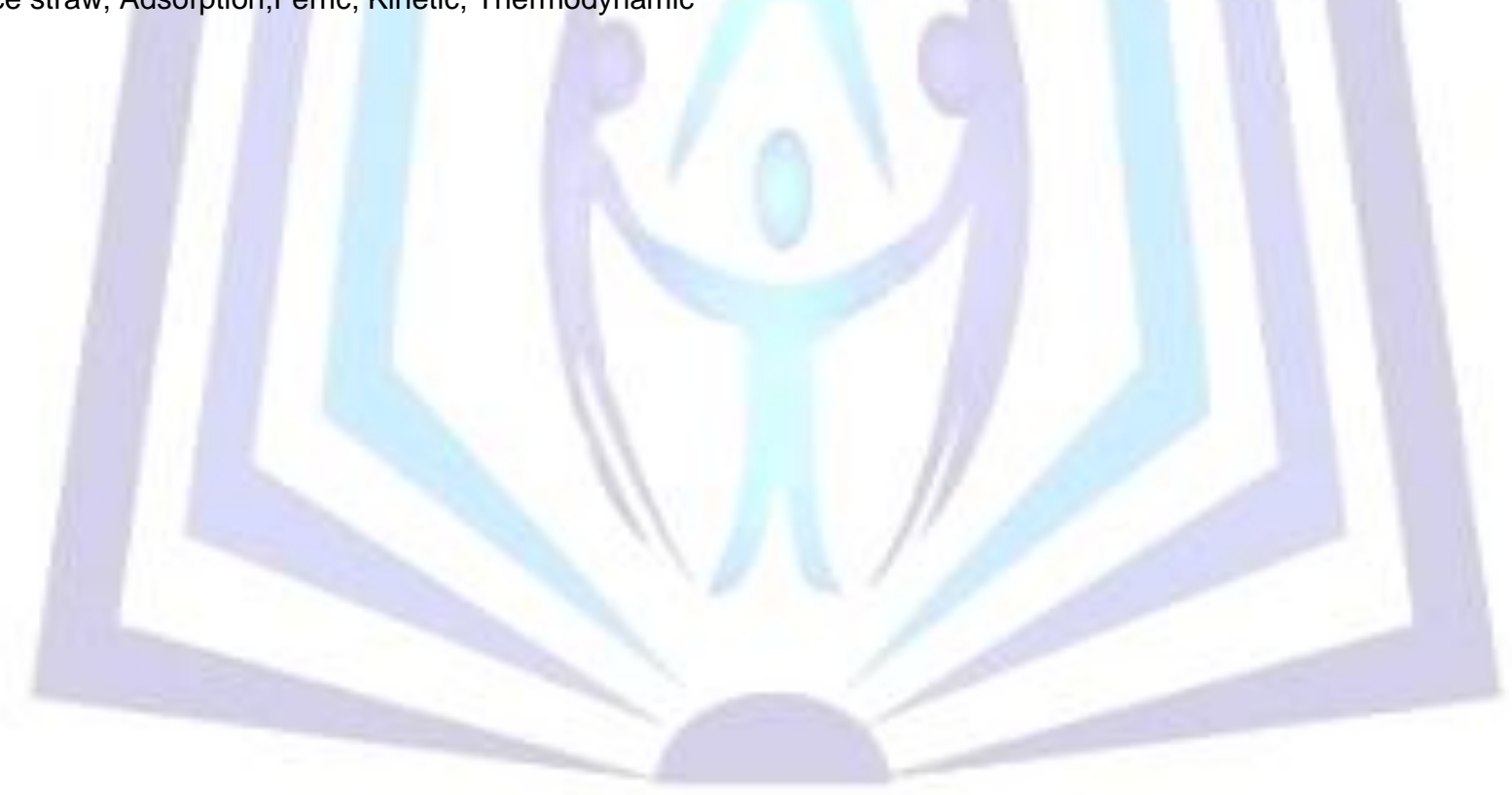

\section{Council for Innovative Research}

Peer Review Research Publishing System

\section{Journal: Journal of Advances in Chemistry}

\author{
Vol.12, No. 3
}




\section{INTRODUCTION}

Water pollution due to toxic heavy metals has been a major cause of concern. The industrial and domestic wastewater is responsible for causing several damages to the environment and adversely affecting the health of the people. Metals can be distinguished from other toxic pollutants, since they are non-biodegradable and can accumulate in living tissues, thus becoming concentrated throughout the food chain.

The main techniques, which have been utilized to reduce the heavy metal ion content of effluents, include lime precipitation, ion exchange, adsorption into activated carbon, membrane process, and electrolytic methods. All these methods are generally expensive. Therefore, numerous approaches have been studied for the development of low-cost adsorbents. Recently,[1,2] reviewed the technical feasibility of various low-cost adsorbents for heavy metal removal and concluded that the use of low-cost adsorbents may contribute to the sustainability of the surrounding environment and offer promising benefits for commercial purpose in the future.

Rice straw is an important agricultural crop residue generated as a by-product during dehusking at rice mills. For every ton of rice processed, rice straw production is estimated to be about 0.23 tons. A large amount of rice straw is burnt in situ, generating $\mathrm{CO}_{2}$ and other forms of pollution. Thus the use of rice straw not only would provide a less costly sorbent to activated carbon or synthetic ion-exchanger as it is cheap and easily available, but will also save the environment from the above-mentioned pollution. Rice straw contains lots of silica. The organic compounds are mainly cellulose, hemicellulose and lignin. It was reported to be good sorbent for a variety of metals cation [3,4].

Alkali treatment of cellulosic fibers with sodium hydroxide $(\mathrm{NaOH})$ is one of the chemical treatments methods that have been employed in order to improve the fiber-matrix interface bonding [5,6]. $\mathrm{NaOH}$ removes natural fats and waxes from the cellulose fiber surfaces thus, revealing chemically reactive functional groups like $-\mathrm{OH}$. The removal of the surface impurities from the cellulose fibres also improves the surface roughness of the fibres or particles, thus opening more hydroxyl groups and other reactive functional groups on the surface [7]. $\mathrm{NaOH}$ may also react with accessible $-\mathrm{OH}$ groups according to the chemical reaction proposed as follow;

$\mathrm{NaOH}+\mathrm{OH}$-rice straws-OH $\rightarrow \mathrm{HO}-$ rice straws-O- $\mathrm{Na}^{+}+\mathrm{H}_{2} \mathrm{O}$

The reaction equations suggest reduction of $-\mathrm{OH}$ groups on the fiber surfaces, which is demonstrated as a decrease in $\mathrm{OH}$ peak intensity in Fourier transform infrared (FTIR) spectra[8] .

Rice straw was selected due to its local availability in abundance, chemical stability and insolubility in water. In the present study, the biosorption efficacy of rice straw for the abatement of $\mathrm{Fe}(\mathrm{III})$ ions from aqueous solutions has been investigated. The changes in the surface and adsorption properties of rice straw modified by $\mathrm{NaOH}$ were monitored by scanning electron microscopy (SEM) and attenuated total reflection (ATR) FTIR spectroscopy.

\section{MATERIAL AND METHODS}

\subsection{Preparation of adsorbents:}

\section{1.a. Rice straw}

The natural rice straw (RS) used in the present experiments was obtained from a market in El-Menoufia Governorate, Egypt. Its chemical compositions are shown in Table 1. The (RS) was thoroughly washed with a stream of distilled water to remove all dirt and then were dried at $110^{\circ} \mathrm{C}$ for $24 \mathrm{~h}$ to constant weight. The dried rice straws were stored in desiccators until used.

\section{1.b. Modified rice straw}

The modified rice straw (MRS) sample was prepared by alkali treatment. Alkali treatment was carried out by placing the RS sample in contact with $\mathrm{NaOH}(0.1 \mathrm{M})$, with constant stirring for $24 \mathrm{~h}$. The liquid/solid ratio was $10 \mathrm{~mL} / \mathrm{g}$. The slurry was allowed to settle for $24 \mathrm{~h}$. It was then filtered, washed $\mathrm{OH}^{-}$free with distilled water, and dried at $110^{\circ} \mathrm{C}$ for $24 \mathrm{~h}$ to constant weight. And it was ground and sieved. The particles $0.63 \mathrm{~mm}$ was selected

and preserved at room temperature in a sealed bottle.

\subsection{Preparation of metal-solutions}

The $\mathrm{Fe}(\mathrm{III})$ stock solution containing $1000 \mathrm{mg} / \mathrm{L}$ was prepared by dissolving ferric chloride $\left(\mathrm{FeCl}_{3}\right)($ analytical reagent grade) in distilled water. Ferric working solutions in different concentrations was prepared by diluting the $\mathrm{Fe}$ (III) stock solution with distilled water.

\subsection{Analytical technique:}

The concentrations of the Fe(III) metal ions were performed using Flame Atomic Absorption Spectrophotometer (FAAS) Vario 6 . Elements were determined using an air- acetylene flame. 


\section{RESULTS AND DISCUSSION}

\subsection{Characterization of adsorbents}

\subsubsection{Chemical composition}

The chemical composition of the rice straw was determined at each stage of treatment and the data are summarized in Table 1.

Table 1 : Chemical Characterization of RS and MRS

\begin{tabular}{|c|c|c|c|}
\hline \multirow{2}{*}{ No. } & \multirow{2}{*}{ Chemical Characterization } & \multicolumn{2}{|c|}{ Samples } \\
\cline { 3 - 4 } & & RS & MRS \\
\hline $\mathbf{1}$ & Moisture Content \% & 7 & 6.65 \\
\hline $\mathbf{2}$ & Ash Content \% & 6 & 13.3 \\
\hline $\mathbf{3}$ & Lignin Content \% & 12.5 & 13 \\
\hline $\mathbf{4}$ & Holocellulose \% & 75.5 & 72.8 \\
\hline $\mathbf{5}$ & Alpha Cellulose & 56 & 61 \\
\hline
\end{tabular}

\subsubsection{FTIR spectra}

The rice straw is constituted basically by cellulose, hemicellulose, lignin, extractives, water and mineral ash which is in large amount $\mathrm{SiO} 2$. The lignin is promptly available to interact with cations, by firstly exchanging with protons and subsequently by chelating with the metallic ion.

The results of ATR-FTIR of the outer surfaces of $\mathrm{NaOH}$ treated and untreated rice straws are shown in Fig. 1(a,b). The term outer surface of rice straw means the outer part of the paddy grain before hulling and inner surface is that part of the paddy that houses the edible rice grain. A medium broad absorption band was found around the region of $\sim 3300 \mathrm{~cm}^{-1}$ for untreated rice straws. This band is due to stretching vibration of intermolecular hydrogen bonded - $\mathrm{OH}$ groups in cellulose fibers [9].

After modification with $\mathrm{NaOH}$ the absorption band shifts to higher frequencies by $\sim 26 \mathrm{~cm}^{-1}$. This is an indication of the presence of free - $\mathrm{OH}$ groups which do not take part in hydrogen bonding [9]. However, there was no evidence of a decrease in the intensities of these peaks possibly due to reaction of accessible $-\mathrm{OH}$ groups and $\mathrm{NaOH}$ as proposed by earlier researchers [10].

A similar trend occurred to the other $-\mathrm{OH}$ groups absorption peaks around $1626 \pm 4 \mathrm{~cm}^{-1}$, which shifted slightly to higher frequencies after treatment with $\mathrm{NaOH}$ suggesting an increase of free $\mathrm{OH}$. Absorption represented by weak bands in the absorption region around $\sim 2925 \pm 1 \mathrm{~cm}^{-1}$ corresponds to the vibration of the carbon-hydrogen bonds superimposed onto -OH broad band around $\sim 3300 \mathrm{~cm}^{-1}$.

Absorption vibration at $\sim 1738 \mathrm{~cm}^{-1}$ appearing on the outer surfaces of the untreated rice straws is due to the vibration of carbonyl from carboxylic groups in ester linkage as proposed by Trejo-O'Reil and Cavaille [11] or due to wax and natural fats. After treating rice straws with $\mathrm{NaOH}$, this peak disappeared, which indicate that it might have been removed by this modification. Another carbonyl vibration occurred at $\sim 1539 \mathrm{~cm}^{-1}$ which could be a spurious band due to carboxylic group vibration or cell windows interaction. This peak disappeared also after increasing the concentration of $\mathrm{NaOH}$.

A medium sharp peak around $\sim 1217 \mathrm{~cm}^{-1}$ due to vibration of silica bonds was observed on the outer surface of untreated rice straws. This peak disappeared on $\mathrm{NaOH}$ treated rice straws. Absence of this peak in $\mathrm{NaOH}$ treated rice straws is an indication of the possibility of sodium hydroxide to react with silica. A decrease in the silica vibration band at $786 \pm 5 \mathrm{~cm}^{-1}$ was observed as the concentration of $\mathrm{NaOH}$ increased. This is another evidence of the possibility of $\mathrm{NaOH}$ to react with silica on the outer surface of rice straws. It is therefore possible that part of the cellulose embedded with silica in the formation of silicon-cellulose membrane on the outer surface of rice straws [12] also degraded during disintegration of this membrane and silica. This may have contributed to lack of increase of the $\mathrm{OH}$ group bands on this surface after alkali treatment.

Fig. 1(a,b) shows the FTIR spectra of the inner surfaces of untreated and $\mathrm{NaOH}$ treated rice straws. A broad peak in the region of $\sim 3273.5 \pm 57 \mathrm{~cm}^{-1}$ in untreated rice straws is due to hydrogen bonded $-\mathrm{OH}$ in cellulose fibers. There is also a slight shift of the $-\mathrm{OH}$ peak to high frequencies in $\mathrm{NaOH}$ treated rice straws. The shift of this peak by about $49 \mathrm{~cm}^{-1}$ to high frequencies suggests presence of free $\mathrm{OH}$. The intensity of this peak is relatively weak for untreated rice straws, but increases progressively with the increase in the concentration of $\mathrm{NaOH}$. The reason behind this could probably be due to the removal of surface impurities from the surface of rice straws thus exposing more reactive - $\mathrm{OH}$ groups on these surfaces, which were detected by ATR-FTIR.

Weak absorption bands around $\sim 2919.5 \pm 0.5 \mathrm{~cm}^{-1}$ due to $\mathrm{C}-\mathrm{H}$ vibration appears immediately after treatment of rice straws with $\mathrm{NaOH}$. This is another evidence of the removal of impurities from the inner surface of rice straws by $\mathrm{NaOH}$. The absorption band around $\sim 1614 \pm 19 \mathrm{~cm}^{-1}$ by a medium, stretching bond may be due to $-\mathrm{OH}$ vibration whose intensity increased after treatment. The absorption peak around $1201-1156 \mathrm{~cm}^{-1}$ occurs in the vibration range of silica bonds. 
This band is common to all the spectra with no evidence of significant change in intensity after treatment. Another absorption corresponding to the absorption frequency of silica bonds appearing around $790 \mathrm{~cm}^{-1}$ for untreated rice straws disappeared in $\mathrm{NaOH}$ treated rice straws except for the one treated with $0.1 \mathrm{M} \mathrm{NaOH}$. However, no evidence of silica composition on the inner surface of rice straws has been reported in previous studies [12].

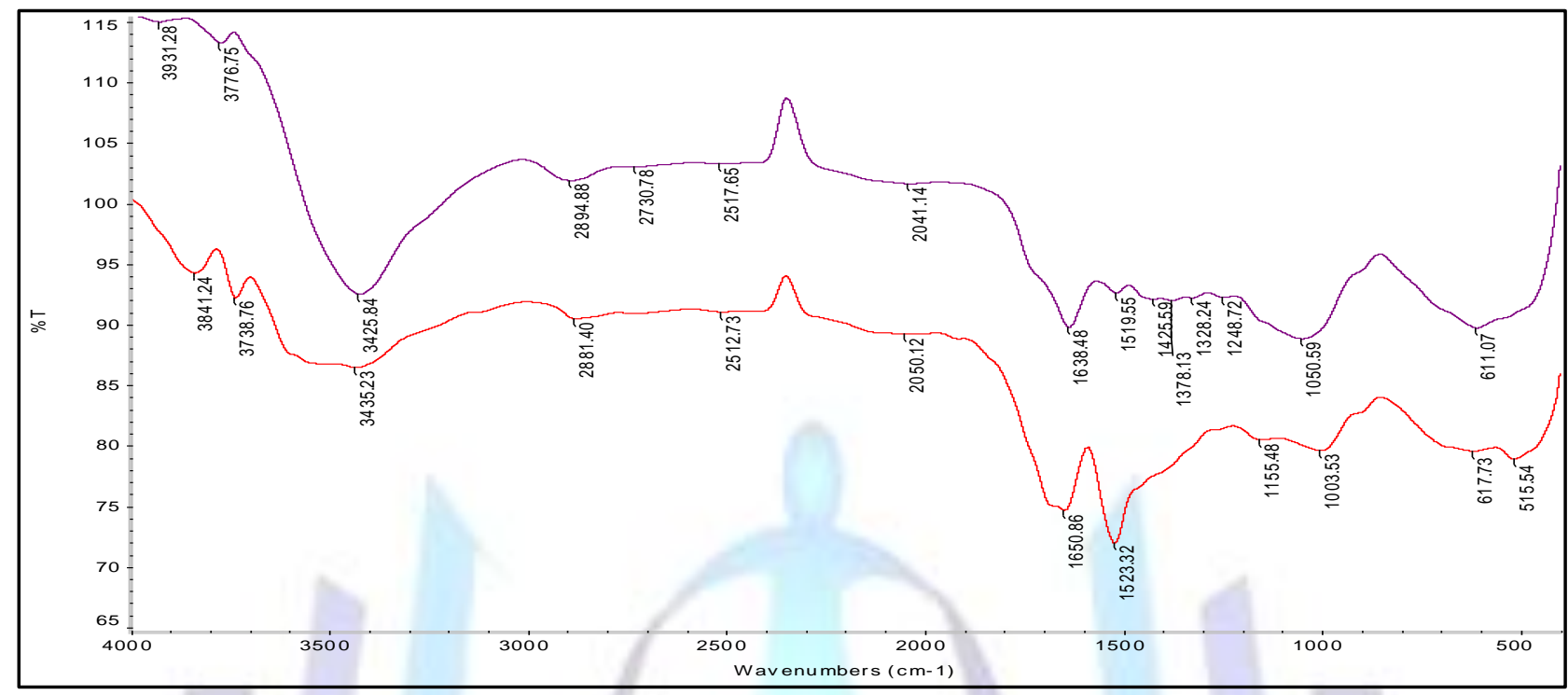

Figure 1 FTIR spectra for (a) RS and (b) MRS before adsorption.

\subsubsection{Scanning electron}

Scanning electron (SEM) micrographs of untreated and treated rice straws are shown in Fig. 2(a,b). As shown in Fig. $2(a, b)$ the surface roughness of the outer and inner surfaces of rice straws change significantly after alkali treated with $\mathrm{NaOH}$. Changes started to be substantial when the rice straws were treated with $\mathrm{NaOH}$. These include wearing of asperities on the outer surfaces and particle cracking which suggests the weakening of the rice straws due to increase in brittleness. The result of Scanning Electron Microscopy (SEM) also shows that rice straw is a porous material [13].
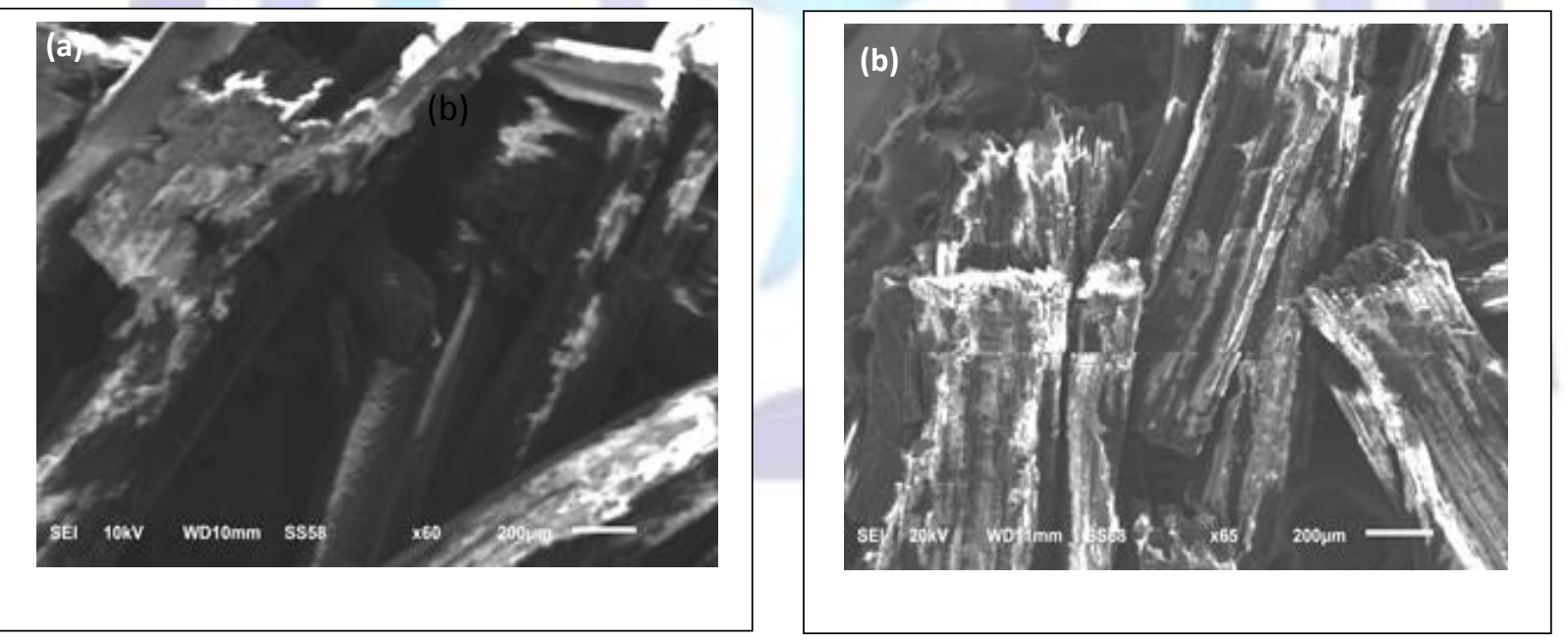

Figure 2 SEM image for (a) RS and (b) MRS before adsorption.

\subsubsection{EDXA Spectra}

Fig. 3(a,b) shows the EDXA spectra of RS and MRS adsorbents before and after loading with Fe(III) respectively. Fig. $3(a, b)$, indicates the presence of major constituents - carbon and oxygen in the two samples adsorbents. Comparing the spectra of the MRS loaded with Fe(III) with that of unloaded one, the cobalt peak could be observed. It was suggested that heavy metals including $\mathrm{Fe}$ (III) had been adsorbed on the surface of MRSsuccessfully. Moreover, after loading with heavy metal, a distinct increase of silica peak intensity could be found. This phenomenon might be derived from the alkali

treatment [14]. 

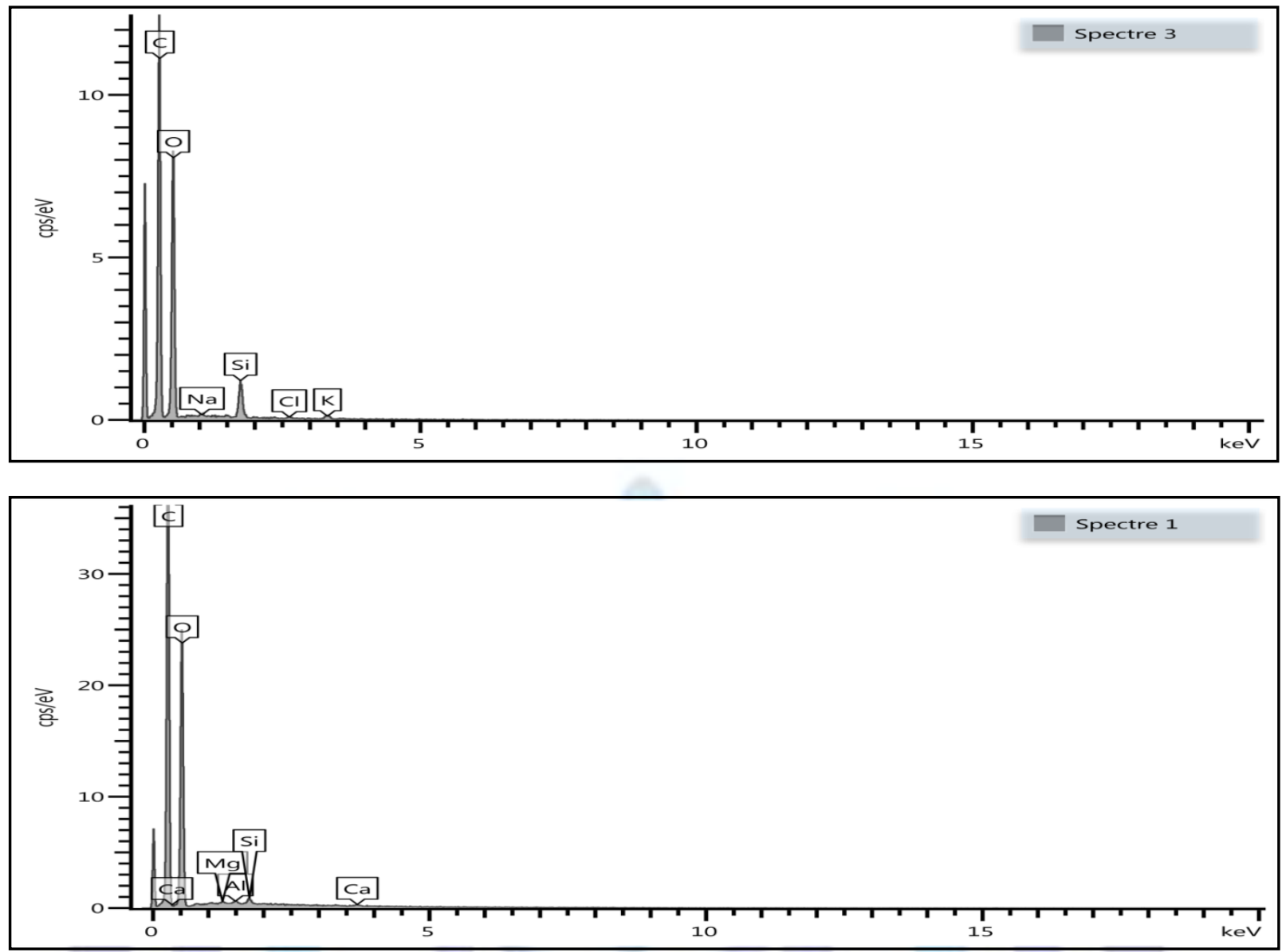

Figure 3 EDXA for (a) RS and (b) MRS before adsorption.

\subsubsection{X-ray diffraction}

Fig. 4(a,b) shows the X-ray diffraction patterns of RS and MRS biosorbents powder. Diffraction peaks corresponding to crystallinity were not observed, whereas, amorphous form is identified in the biosorbent. The amorphous nature of the biosorbents suggested that the metal ion could more easily penetrate into the surface of the two biosorbents on the amorphous. Optimization of $\mathrm{Fe}(\mathrm{III})$ biosorption by chemically modified rice straw [15].
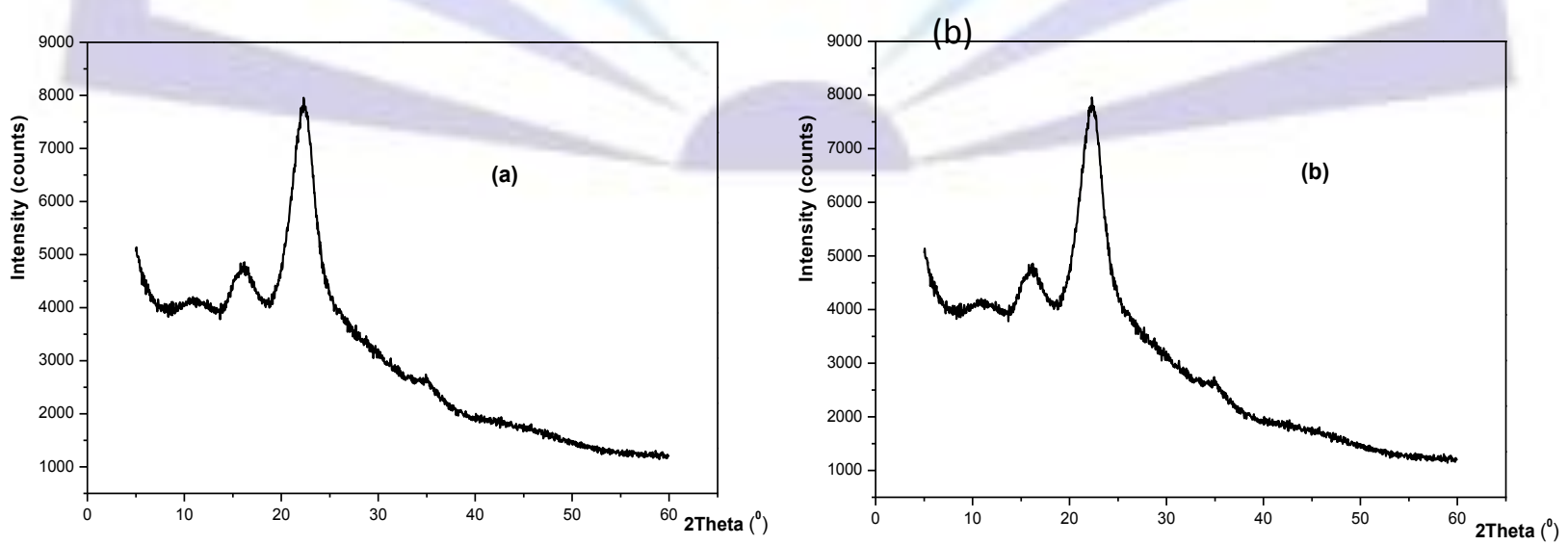

Figure 4 XRD for (a) RS and (b) MRS befor adsorption. 


\subsection{Effect of adsorbent dosage on adsorption}

Fig. $5(a, b)$ shows the removal of ferric as a function of adsorbent dosage using RS and MRS in aqueous solution. The adsorbent dosage varied from 0.1 to $1.0 \mathrm{~g}$ and equilibrated for $\approx 5 \mathrm{~h}$. It is clear from fig.5(a,b) that for the maximum removal percentage of 85.9 and $53.3 \%$ of ferric requires a maximum RS and MRS dosage of $1.0 \mathrm{~g}$ for, respectively. The data clearly shows that all the adsorbents have a high level of performance in terms of the removal of ferric. The observed differences may be due to the high adsorption capacity of RS. It may be concluded that by increasing the adsorbent dose the removal efficiency increases but adsorption density decreases. The decrease in adsorption density can be attributed to the fact that some of the adsorption sites remain unsaturated during the adsorption process; whereas the number of available adsorption sites increases by an increase in adsorbent and these results in an increase in removal efficiency.

As expected, the equilibrium concentration decreases with increasing adsorbent doses for a given initial ferric concentration, because for a fixed initial solute concentration, increasing the adsorbent doses provides a greater

surface area or adsorption sites [16].
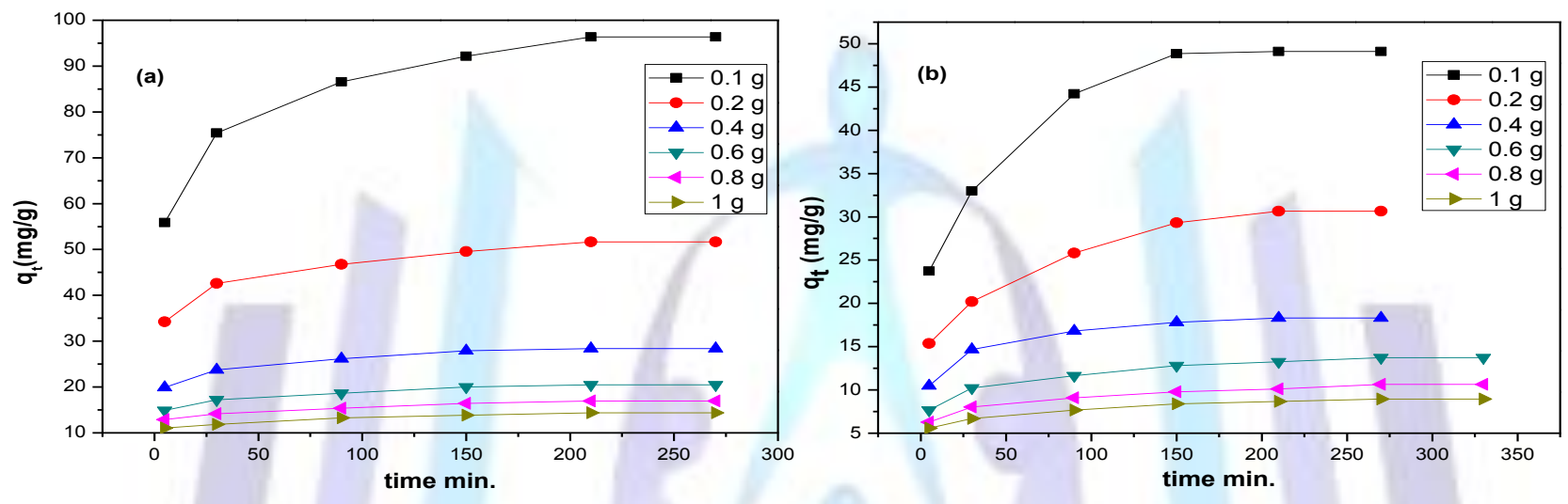

Figure 5 The effect of amount of (a) RS and (b) MRS on the removal of $\mathrm{Fe}(\mathrm{III})$ at $28{ }^{\circ} \mathrm{C}$.

\subsection{Effect of initial ferric concentration}

The Fe(III) adsorption capacity increased with the Fe(III) equilibrium concentration increasing from 111.7 to $781.9 \mathrm{mg} / \mathrm{L}$. This capacity of the RS was ranged from 23.1 to $40 \mathrm{mg} / \mathrm{g}$ and from 13 to $22.6 \mathrm{mg} / \mathrm{g}$, of MRS, respectively. On the other hand, we can observe that, with an increase of the Fe(III) equilibrium concentration, the removal percentage of ferric, show an opposite trend where, the removal percentage was decreased from 78.8 - to $40.9 \%$ and from 93.1 to $23.1 \%$. The results of the Fe(III) adsorption experiments are shown in Fig. 6.Actually, as the initial concentrations of Fe(III) increased, the driving force became higher as well, the accessibility of the heavy metal ions to the binding sites of the MRS is relatively high with increased initial concentration, the ions exchange frequently and the uptake of heavy metals becomes more and more [17].

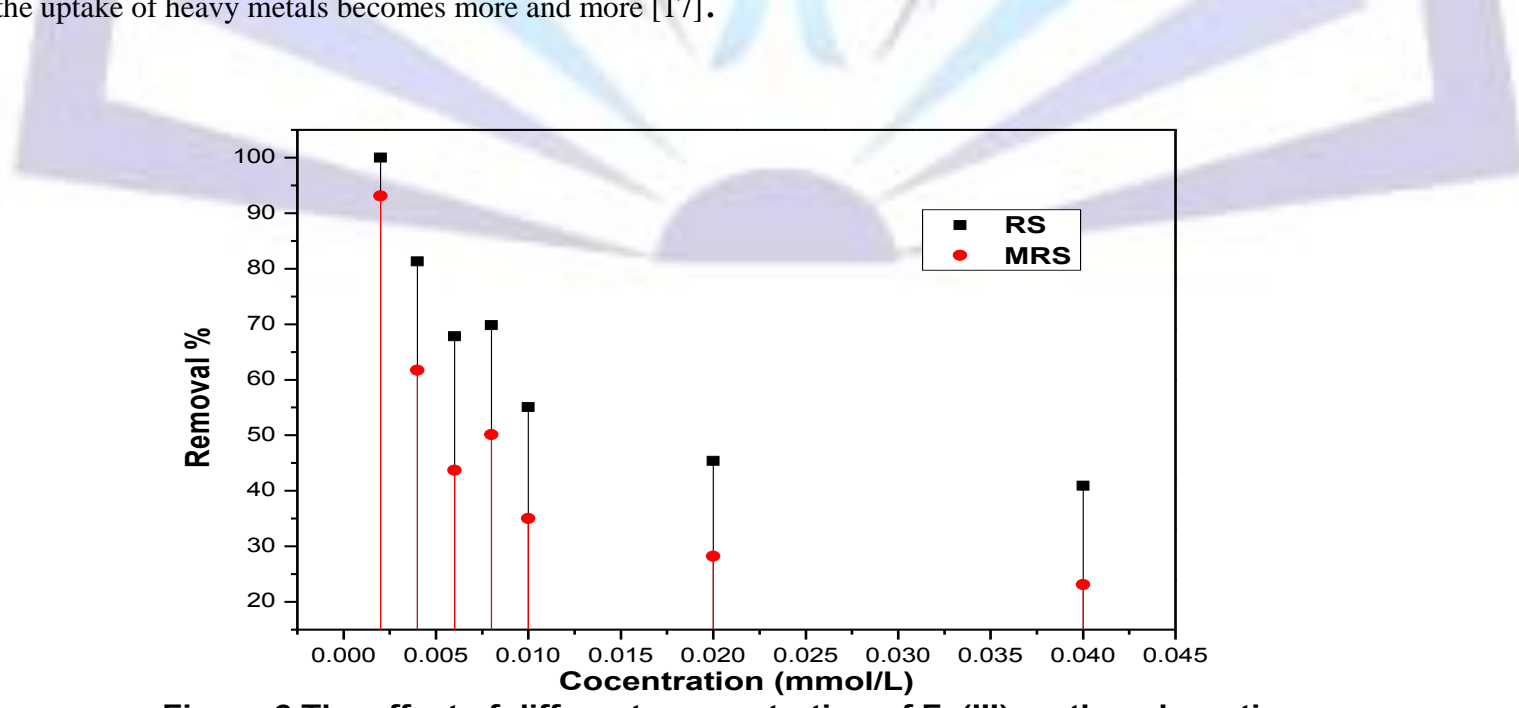

Figure 6 The effect of different concentration of Fe(III) on the adsorption. 


\subsection{Effect of $\mathrm{pH}$ on $\mathrm{Fe}(\mathrm{III})$ adsorption}

The effect of $\mathrm{pH}$ on the $\mathrm{Fe}(\mathrm{III})$ adsorption on the two adsorbents for a $\mathrm{pH}$ between 1.0 and 2.9 is presented in fig.7. It can be found that the removal efficiency, increased with increase $\mathrm{pH}$ for both adsorbents. The uptake of Fe(III) by RS and MRS increased as the $\mathrm{pH}$ increased from 1.0 to 2.5. At higher $\mathrm{pH}$ value, 2.9 the removal efficiency decreased for both adsorbents. Although a maximum uptake was noted at a $\mathrm{pH}$ of 2.5 , as the $\mathrm{pH}$ of the solution increased to $>2.5 \mathrm{Fe}$ (III) started to precipitate out from the solution. Therefore, the increased capacity of adsorption at $\mathrm{pH}=2.5$ may be a combination of both adsorption and precipitation on the surface of the adsorbents. It is considered that adsorbents had a maximum adsorption capacity at a $\mathrm{pH}=2.5$, if the precipitated amount is not considered in the calculation. Therefore, the optimum $\mathrm{pH}$ for Fe(III) adsorption is 2.5 .

The $\mathrm{pH}$ of the aqueous solution is an important variable that influences the adsorption of anions and cations at the solid-liquid interfaces. As can be seen from Fig. 7, the $\mathrm{pH}$ value of the ferric solution plays an important role in the whole adsorption process and particularly on the adsorption capacity. The Fe(III) adsorption on the two adsorbents tends to increase with the increase of $\mathrm{pH}$. This is likely attributed to the fact that a lower $\mathrm{pH}$ value causes the surface to carry more positively charges and thus would more significantly repulse the positively charged species in solution. Therefore, the lower adsorption of Fe(III) at lower pH values resulted from an increased repulsion between the more positively charged Fe(III) species and positively charged surface sites. Furthermore, at lower $\mathrm{pH}, \mathrm{H}^{+}$ions compete with $\mathrm{Fe}(\mathrm{III})$ ions to the surface binding-sites of the adsorbent [18-20].

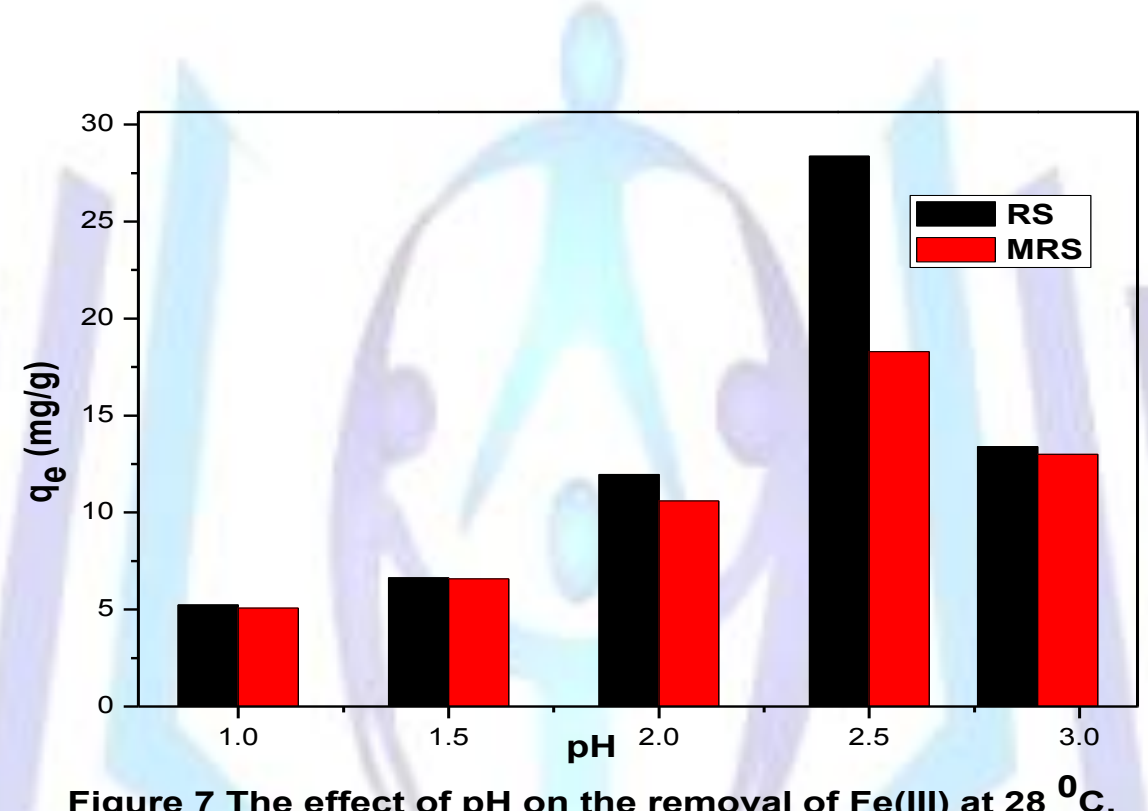

\subsection{The distribution ratio (D)}

Distribution ratio $D$ for ferric ions was determined by the batch method at different temperature systems ( 301,313 and $323 \mathrm{~K})$. The distribution ratio, $\mathrm{D}$, is defined as the ratio of metal ion concentration on the adsorbent to that in the aqueous solution and can be used as a valuable tool to study Fe(III) ion mobility. The distribution ratio $D$ is defined by the following relationship [21,22]:

$\mathrm{K}_{\mathrm{d}}=\frac{(I-F)}{500 \mathrm{mg}} \times \frac{50 \mathrm{ml}}{F}$

Where $I$ is the volume of EDTA used before treatment of metal ion-exchanger. $F$ is the volume of EDTA consumed by metal ion left in solution phase.

Various portions of $(0.4 \mathrm{~g}$ each) the adsorbent were taken in Erlenmeyer flasks and mixed with $50 \mathrm{ml}$ of metal ion solution in the aqueous medium and subsequently shaken for $24 \mathrm{~h}$ in temperatures controlled shaker at 301,313 and $323 \mathrm{~K}$ to attain the equilibrium. Fig. 8 shows that the distribution ratio(D) values increase with the increase in temperatures of ferric solutions from 301 to $313 \mathrm{~K}$ then decrease at higher temperature (323K). However, the distribution ratio of Fe(III) between ferric solution and MRS show a gradual increases at increase of temperature. High values of the distribution ratio (as in aqueous-RS systems at low temperature), indicate that the metal has been retained by the solid phase through sorption reactions, while lower values of $D$ (as in aqueous-MRS systems at low temperature), indicate that a large fraction of the metal remains in solution. The rapid metal sorption has significant practical importance, as this will facilitate with the small amount of resin to ensure efficiency and economy. 
According to the above results of the Fe(III) adsorption experiments, the RS had higher adsorption capacities than the MRS. It was believed that the surface structural changes of the material play the most important role in the adsorption capacities of the $\mathrm{Fe}(\mathrm{III})$. When the RS sample was treated with $0.1 \mathrm{M} \mathrm{NaOH}$, the surface structure of the RS was changed, which can be seen from the FTIR spectra of the MRS.

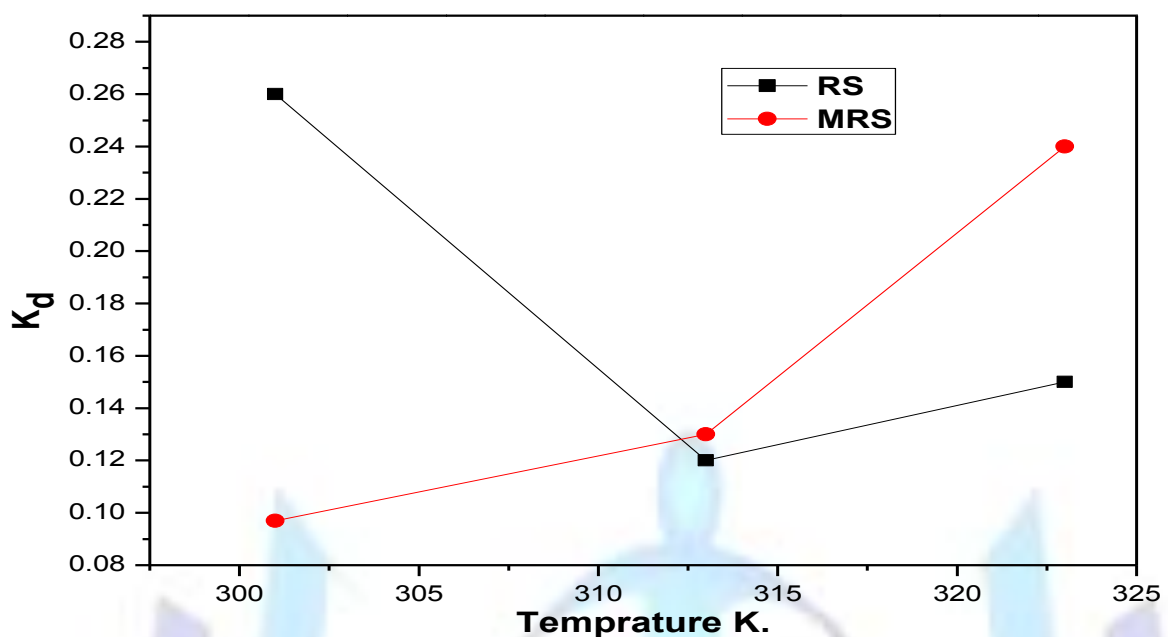

figure 8 The effect of distribution coofficint on adsorption of Fe(III).

\subsection{Adsorption isotherms}

The equilibrium adsorption isotherms of ferric ions were determined at three different temperatures ( 301,313 and $323 \mathrm{~K})$. The experimental data were fitted to linear equations of Freundlich $[23,24]$, Langmuir $[25,26]$, Temkin $[27,28]$ and Dubinin and Radushkevich [29,30], isotherm models.

Two typical isotherms, as described below in Eq. (1) and (2), were used for fitting the experimental data:

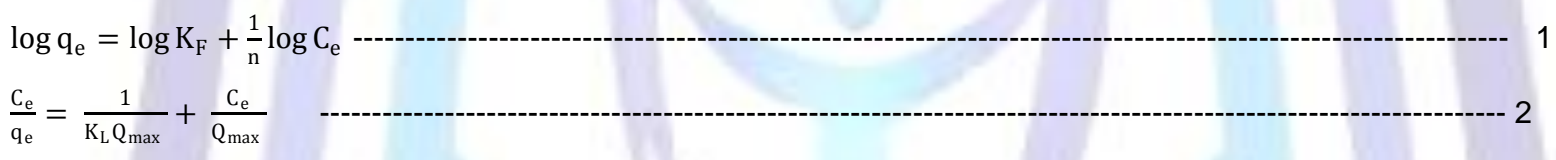

Where $q_{\mathrm{e}}$ is the amount adsorbed at equilibrium $(\mathrm{mg} / \mathrm{g})$, and $C_{e}$ is the equilibrium concentration $(\mathrm{mg} / \mathrm{L})$. The other parameters are different isotherm constants, which can be determined by the correlation coefficient of the experimental data. The value of $(n)$ is a characteristic constant measure of intensity of sorption. The values of $(n)$ computed from the slope of the plots of Freundlich equation (Fig. not shown) (1.5 and 1.3 for ferric on both RS and MRS, respectively) and the results of $k_{F}(\mathrm{mg} / \mathrm{g})$ estimated from the intercept of the linear plots. $\mathrm{k}_{\mathrm{F}}$ was also 601.3 and 1174.9 of both RS and MRS, respectively, indicate better sorption at the experimental conditions.

A dimensionless constant, separation factor, $R_{\mathrm{L}}$ describes the type $\left(R_{\mathrm{L}}=0\right.$ irreversible, $R_{\mathrm{L}}$ between 0 and 1 favourable and unfavourable $\left(R_{\mathrm{L}}>1\right)$ of Langmuir isotherm, which is an essential characteristic of Langmuir isotherm and may be calculated in the temperature range (301-323K) for cobalt ion, by employing the relationship;

$\mathrm{R}_{\mathrm{L}}=1 / 1+\mathrm{K}_{\mathrm{L}} \mathrm{C}_{\mathrm{i}}$

Where ' $K_{L}$ ' is the Langmuir constant $\left(\mathrm{L} \mathrm{mol}^{-1}\right)$ and $C_{\mathrm{i}}$ is the initial concentration of sorbate $(\mathrm{mg} / \mathrm{g})$. In linear Plots of $C_{\mathrm{e}} / q_{e}$ versus $C_{\mathrm{e}}$ (Fig. not shown), the values of $Q_{\max }$ are analyzed from the slope of the linear plots and its values are 188 and $12.2 \mathrm{mg} / \mathrm{g}$ of RS and MRS, respectively, whereas the values of ' $K_{L}^{\prime}$ ' $\left(1.4 \times 10^{-3}\right.$ and $0.016 \mathrm{~mol} \mathrm{~L}^{-1}$ of $\mathrm{RS}$ and MRS, respectively) for $\mathrm{Fe}(\mathrm{III})$ are computed from the intercepts of the plots. The values of $R_{\mathrm{L}}$ are 0.68 and 0.16 of RS and MRS, respectively; assign a highly favorable sorption at whole solution temperatures studied herein.

Dubinin-Radushkevich (D-R) isotherm is another adsorption model isothermapplied in the linearized form of the equation(3) as,

$\operatorname{Lnq}=\ln X_{m}-\beta \varepsilon^{2}$

Where $q_{e}$ is in $(\mathrm{mg} / \mathrm{g})$ (described earlier), $X_{\mathrm{m}}((\mathbf{m g} / \mathrm{g}))$ represents the maximum sorption capacity of sorbent and $\beta$ $\left(\mathrm{kJ}^{2} \mathrm{~mol}^{-2}\right)$ is a constant with dimensions of energy. The Polanyi sorption potential $\varepsilon$, which is the amount of energy required to pull a sorbed molecule from its sorption site to infinity may be evaluated by using relationship equation (4) as:

$\varepsilon=\mathrm{RT} \ln \left(1+1 / \mathrm{C}_{\mathrm{e}}\right)$ 4

Where ' $R$ ' is a gas constant in $\mathrm{kJ} \mathrm{mol}^{-1} \mathrm{~K}^{-1}, ' T$ is the temperature in Kelvin, $C_{\mathrm{e}}(\mathrm{mg} / \mathrm{g})$ is as mentioned earlier. The plots of In $q_{\mathrm{e}}$ versus $\varepsilon^{2}$ yield a poor coefficients $(\approx 97$ and 92$)$ and the results of $X_{\mathrm{m}}$ computed from the slope and intercept of the 
respective plots (Fig. not shown) $\left(21.1\right.$ and $15.8(\mathrm{mg} / \mathrm{g})$. The values of sorption energy, Ewas 3.4 and $21.9 \mathrm{~kJ} \mathrm{~mol}^{-1}$ of both $\mathrm{RS}$ and MRS, respectively, for Fe(III)) are calculated[31] using the relationship in equation (5)as:

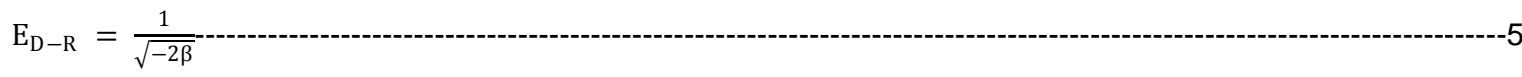

These values indicate physical and chemical processes for ferric-RS and -MRS systems, respectively. The Temkin isotherm has been used in the following equation (6):

$\mathrm{q}_{\mathrm{e}}=\mathrm{B}_{\mathrm{T}} \ln \mathrm{A}_{\mathrm{T}}+\mathrm{B}_{\mathrm{T}} \ln \mathrm{C}_{\mathrm{e}}$

Where $R$ is gas constant $\left(8.314 \mathrm{~J} \mathrm{~mol}^{-1} \mathrm{~K}^{-1}\right)$, $T$ is temperature $(K), A_{T}$ is the equilibrium binding constant $\left(L g^{-1}\right)$ corresponding to the maximum binding energy, and constant $B_{T}=\left(R T / b_{T}\right)$ is related to the heat of adsorption. $A$ plot of $q_{e}$ versus $\ln C_{e}$ (Fig. not shown) is used to calculate the Temkin isotherm constants $A_{T}$ and $B_{T}$.

The values of $\mathrm{B}_{\mathrm{T}}(\mathrm{J} / \mathrm{mol})$ are analysed from the slope of the linear plots and its values are 17.0 and $18.4 \mathrm{mg} / \mathrm{g}$ of $\mathrm{RS}$ and MRS, respectively, whereas the values of $A_{T}\left(1.7 \times 10^{-3}\right.$ and $\left.1.97 \times 10^{-3} \mathrm{~L} / \mathrm{g}\right)$ of $\mathrm{RS}$ and MRS, respectively, for Fe(III) are computed from the intercepts of the plots.

From our results we can concluded that the experimental data of $\mathrm{Fe}(\mathrm{III})$ adsorption on RS sample could be well fitted by the isotherms. Clearly, the temkin equation provided better fitting in terms of $R^{2}$ values (0.99082). However, the fitting order of the different adsorption models according to $R^{2}$ was as follows; Temkin $(0.99082)>$ Langmuir $(0.99037)>$ Freundlich (0.98752) > D - R (0.97017).on the other hand, the adsorption of Fe(III) on MRS provided better fitting of the temkin equation in terms of $R^{2}$ values (0.99556). However, the fitting order of the different adsorption models according to $\mathrm{R}^{2}$ was as follows; Temkin $(0.99556)>$ Langmuir $(0.97732)>$ Freundlich $(0.96688)>D-R(0.92946)$.

\subsection{Adsorption kinetics}

Kinetic studies were carried out using different models, namely, pseudo-first order [32,33], pseudo-second order [34,35], Elovich [36] and Fickian diffusion intraparticle [37,38] models to analyze the experimental data.

The results of the $\mathrm{Fe}$ (III) adsorption kinetic experiments at the $28^{\circ} \mathrm{C}$ show that the majority of $\mathrm{Fe}$ (III) adsorption on the adsorbents was completed in 3-4 h. For example, after 210 min of adsorption, the Fe(III) adsorbed on the RSandMRS was, respectively, $67.8 \%$ and $43.7 \%$ of that at equilibration time. And the removal percentage of ferric from the solutions by RSwas higher than the MRS sample, which can be attributed to the surface structural changes of the material.

The adsorption kinetics, demonstrating the solute uptake rate, is one of the most important characteristics, which represents the adsorption efficiency of the samples. The Fe(III) adsorption kinetic data ((Fig. not shown)) were fitted with pseudo-first-order rate equation of Lagergren and pseudo-second-order rate equation of linear equations.

The pseudo-first-order kinetic model is given equation (7) as:

$\log \left(\mathrm{q}_{\mathrm{e}}-\mathrm{q}_{\mathrm{t}}\right)=\log \mathrm{q}_{\mathrm{e}, 1}-\mathrm{k}_{1} \mathrm{t}$

The pseudo-second-order equation is expressed equation $(8,9)$ as:

$\frac{\mathrm{t}}{\mathrm{q}_{\mathrm{t}}}=\frac{1}{\mathrm{k}_{2} \mathrm{q}_{\mathrm{e}, 2}^{2}}+\frac{\mathrm{t}}{\mathrm{q}_{\mathrm{e}, 2}}$

$\mathrm{h}=\mathrm{k}_{2} \mathrm{q}_{\mathrm{e}, 2}^{2}$

Where $k_{1}$ is the Lagergren adsorption rate constant $\left(\mathrm{min}^{-1}\right)$ and $k_{2}$ is the pseudo-second-order adsorption rate constant $\left(\mathrm{g} /(\mathrm{mg} \mathrm{h}) ; q_{e}\right.$ and $q_{t}$ are the amounts of $\mathrm{Fe}(\mathrm{III})$ absorbed $(\mathrm{mg} / \mathrm{g})$ at equilibrium and time $t$, respectively. Based on $R^{2}$ obtained, the kinetics of Fe(III) adsorption on the RS (0.99862) and MRS(0.99873) can be satisfactorily described by the pseudo-second-order equations at $301 \mathrm{~K}$ as in table 2.

Therefore, the fitting curves resulting from both equations are plotted (Fig. not shown). The high applicability of the pseudo-second-order equation for the present kinetic data is generally in agreement with other researchers' results that the pseudo-second-order equation was able to describe properly the kinetics of $\mathrm{Fe}(\mathrm{III})$ adsorption $[39,40]$. On the other hand, when the temperature was increased, the initial adsorption rate $\mathrm{h}(\mathrm{mmol} /(\mathrm{g} \mathrm{min}))$ of RS and MRSdecreased from 5.4 to 0.78 and from 2.6 to $1.4 \mathrm{mg} /(\mathrm{g} \mathrm{min})$. The value $(\mathrm{h})$ for $\mathrm{RS}$ was higher than that of MRS at low temperature, suggesting that $\mathrm{RS}$ possesses the fastest kinetics among two adsorbents as in table 2.

For Fickian diffusion law, all the correlation coefficients were relatively low and the intercept of plots revealed obvious boundary layer effect (Fig. not shown). Larger intercept means a greater contribution of surface adsorption as the ratecontrolling step. In addition, it was essential for the plots of $q_{t}$ versus $t^{0.5}$ to go through the origin if the intra-particle diffusion was the sole rate-limiting step. However, all the linear portions did not pass through the origin (all intercepts were in the range of0.93914 - 0.97118 and $0.87999-0.95641$ of RS and MRS, respectively), indicating that intra-particle diffusion maybe not only the rate-controlling factor [41]. This was further evidence indicating that the active sites of the two adsorbents are mainly distributed on the external surface. The adsorption rate of RS was faster than MRS because of its higher external surface area. Therefore, the external surface of the adsorbent was the key factor in the rate-controlling as in Table 2. 
Table 2 : Kinetic parameters for $(6 \mathrm{mmol} / \mathrm{L})$ of $\mathrm{Fe}(\mathrm{III})$ on on $\mathrm{RS}$ and MRS in aqueous solution.

\begin{tabular}{|c|c|c|c|c|c|c|c|c|c|c|c|}
\hline \multirow{2}{*}{ 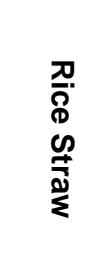 } & \multirow[b]{2}{*}{$\frac{10}{3}$} & \multicolumn{3}{|c|}{ Pseudo first-order model } & \multicolumn{4}{|c|}{ Pseudo second-order model } & \multicolumn{3}{|c|}{$\begin{array}{l}\text { Intraparticle diffusion } \\
\text { model }\end{array}$} \\
\hline & & $\begin{array}{l}q_{e, 1, c a l} \\
(m g / g)\end{array}$ & $\begin{array}{c}\mathrm{K}_{1} \\
\left(\mathrm{~min}^{-1}\right)\end{array}$ & $\mathbf{R}^{2}$ & $\begin{array}{c}q_{e, 2, \text { cal }} \\
(\mathrm{mg} / \mathrm{g})\end{array}$ & $\begin{array}{c}\mathrm{K}_{2} \\
(\mathrm{~g} / \mathrm{mg} \\
\mathrm{min})\end{array}$ & $\begin{array}{c}\mathrm{h} \\
(\mathrm{mg} / \mathrm{g} \\
\mathrm{min})\end{array}$ & $\mathbf{R}^{2}$ & $\begin{array}{c}\mathrm{K}_{\text {int }} \\
\mathrm{mg} / \mathrm{g} \\
\mathrm{min}^{-0.5}\end{array}$ & $\begin{array}{c}C \\
(\mathrm{mg} / \mathrm{g})\end{array}$ & $\mathbf{R}^{2}$ \\
\hline \multirow{3}{*}{ RS } & 301 & 9.50 & 0.0194 & 0.96467 & 28.89 & $6.4 \times 10^{-3}$ & 5.4 & 0.99862 & 0.686 & 19.197 & 0.93914 \\
\hline & 313 & 16.22 & 0.0162 & 0.90001 & 25.79 & $9.2 \times 10^{-3}$ & 0.16 & 0.95001 & 0.934 & 5.987 & 0.96538 \\
\hline & 323 & 17.22 & 0.0171 & 0.916825 & 28.99 & $9.3 \times 10^{-3}$ & 0.78 & 0.95498 & 0.954 & 8.492 & 0.97118 \\
\hline \multirow{3}{*}{ MRS } & 301 & 7.41 & 0.0181 & 0.98212 & 18.74 & $7.4 \times 10^{-3}$ & 2.6 & 0.99873 & 0.612 & 10.222 & 0.87999 \\
\hline & 313 & 12.02 & 0.0170 & 0.98829 & 22.07 & $3.7 \times 10^{-3}$ & 1.8 & 0.99778 & 0.756 & 10.107 & 0.92768 \\
\hline & 323 & 21.38 & 0.0173 & 0.95086 & 29.27 & $1.6 \times 10^{-3}$ & 1.4 & 0.99299 & 1.240 & 8.789 & 0.95641 \\
\hline
\end{tabular}

\subsection{Effect of temperature}

The equilibrium removal of $\mathrm{Fe}(\mathrm{III})$ ions as a function of temperature, for experiments conducted at constant concentrations of $\mathrm{Fe}$ (III) equal to $335.01 \mathrm{mg} / \mathrm{L}$. The adsorption of $\mathrm{Fe}(\mathrm{III})$ onto the surface of both RS and MRS place quickly regarding the temperature $(301-323 \mathrm{~K})$. On the other hand, enhancement of the adsorption capacity of the MRS at higher temperatures may be attributed to the activation of the adsorbing surface and increase in the mobility of metal ions. Also, this fact demonstrated an endothermic biosorption process.

The removal percentage of cobalt onto the RS and MRS adsorbents (Fig. not shown) was increased with increase of temperatures at low 301 and $313 \mathrm{~K}$ then decrease at higher temperature (323K)for RS. However, the removal percentage by MRS was increases with increase in temperature from 301 to $323 \mathrm{~K}$. This may be due to the formation of new active sites in the adsorbents to increase in temperature, activation of the adsorbing surface and increase in the mobility of metal ions. An increase of adsorption capacities of $\mathrm{Fe}(\mathrm{III})$ on the two adsorbents as the temperature increased, indicating also an endothermic process and a possible type of chemical adsorption mechanism occurs.

\subsection{Thermodynamics of sorption}

Thermodynamic parameters, enthalpy $\Delta H\left(\mathrm{~kJ} \mathrm{~mol}^{-1}\right)$, entropy $\Delta S\left(\mathrm{~J} \mathrm{~mol}^{-1} \mathrm{~K}^{-1}\right)$ and standard free energy of activation $\Delta G\left(\mathrm{~kJ} \mathrm{~mol}^{-1}\right)$ were investigated in the range of $301-323 \mathrm{~K}$ under the optimized conditions chosen by applying the equations $(10,11)$ as:

$\ln \mathrm{K}_{\mathrm{d}}=\frac{\Delta \mathrm{S}}{\mathrm{R}}-\frac{\Delta \mathrm{H}}{\mathrm{RT}}$ $-10$

$\Delta \mathrm{G}=\Delta \mathrm{H}-\mathrm{T} \Delta \mathrm{S}$

Where ' $R$ ' is a gas constant, ' $T$ is the temperature in Kelvin. The plots of In $K_{d}$ versus $1 / T\left(\mathrm{~K}^{-1}\right)$ are linear throughout the investigation and the values of $\Delta H$ and $\Delta S$ are computed from the respective slopes and intercepts of the plots. The calculated thermodynamic parameters are presented in Table 3. $\Delta \mathrm{H}^{\circ}$ values were negative, demonstrating an exothermic process in ferric-RS system while the $\Delta \mathrm{H}^{\circ}$ values were positive, demonstrating an endothermic process in ferric-MRS system. The positive $\Delta G^{\circ}$ values accompanied by the negative $\Delta S^{\circ}$ suggested that the sorption reactions are nonspontaneous with a low affinity and presence of high energy barrier in case of aqueous ferric-RS system.

On the other hand, the negative $\Delta G^{\circ}$ values and the positive $\Delta S^{\circ}$ suggested that the sorption reactions are spontaneous with a high affinity and alower energy barrier for ferric adsorption using MRS. This is may be due to changes in the surface functional groups of the adsorbent $[42,43]$. 
The positive enthalpy change $\left(\Delta \mathrm{H}^{\circ}\right)$ values for the metal ions adsorption reaction as in table 3 indicate the endothermic nature of the present reaction. $\Delta \mathrm{H}^{\circ}$ values obtained from adsorption of $\mathrm{Fe}(\mathrm{III})$ onto the MRS are lower than that onto RS. This result gives clear evidence that the interactions between $\mathrm{Fe}(\mathrm{III})$ and the surface groups of the RS may be weaker than that of the surface groups of the MRS. The low value of $\Delta \mathrm{H}^{\circ}\left(<40 \mathrm{~kJ} \mathrm{~mol}^{-1}\right)$ for Fe(III)onto both adsorbents indicated that the adsorption process occurs mainly through a physical means. On the other hand, the negative values of $E_{a}(-$ $13.88 \mathrm{~kJ} / \mathrm{mol}$ ) and $\Delta \mathrm{H}^{\circ}$ indicate the presence of high an energy barrier in the adsorption process in case of RS, while, the positive values of $\mathrm{E}_{\mathrm{a}}(20.3 \mathrm{~kJ} / \mathrm{mol})$ and $\Delta \mathrm{H}^{\circ}$ indicate the presence of low an energy barrier in the adsorption process in case of MRS[44].

The positive values for these parameters are quite common because the activated complex in the transition state is in an excited form. The positive entropy change $\left(\Delta S^{\circ}\right)$ for this reaction (Table 3 ) has also indicated the increase in the number of species at the solid-liquid interface and, hence the randomness in the interface which is presumably due to the release of aqua molecules when aquoted metal ion is adsorbed on the surface of the adsorbent and significant changes occur in the internal structure of the adsorbent through the adsorption of the metal ions onto the resin[45].

In order to further support the assertion that the adsorption is the predominant mechanism, the values of the activation energy $\left(E_{a}\right)$ and sticking probability $\left(S^{*}\right)$ were estimated from the experimental data. They were calculated using a modified Arrhenius type equation related to surface coverage as expressed in equations $(12,13)$ as:

$\theta=1-\frac{\mathrm{C}_{\mathrm{e}}}{\mathrm{C}_{0}}$
$\mathrm{~S}^{*}=(1-\theta) \exp \left(-\frac{\mathrm{E}_{\mathrm{a}}}{\mathrm{RT}}\right)$

The sticking probability, $\mathrm{S}^{*}$, is a function of the adsorbate/adsorbent system under consideration and is dependent on the temperature of the system. The parameter $S^{*}$ indicates the measure of the potential of an adsorbate to remain on the adsorbent indefinitely. It can be expressed as in Table 3 .

The effect of temperature on the sticking probability was evaluated throughout the temperature range from 301 to $323 \mathrm{~K}$ by calculating the surface coverage at the various temperatures. Table 3 also indicated that the values of $S^{*} \leq 1$ for MRS, hence the sticking probability of the Fe(III) ion ontoRS are very high. However, the values of $S^{*}>1$ for RS, hence the sticking probability of the Fe(III) ion onto RS are very low [46].

Table 3 : Thermodynamic parameters for $(6 \mathrm{mmol} / \mathrm{L})$ of $\mathrm{Fe}(\mathrm{III})$ on $\mathrm{RS}$ and MRS in aqueous solution.

\begin{tabular}{|c||c||c|c||c|c||c||}
\hline \multirow{2}{*}{ Rice Straw } & Temp.K & $\begin{array}{c}\Delta \mathbf{G} \\
\mathbf{( k J / m o l})\end{array}$ & $\begin{array}{c}\Delta \mathbf{S} \\
\mathbf{( J / m o l ~ k )}\end{array}$ & $\begin{array}{c}\Delta \mathbf{H} \\
\mathbf{( K J / m o l})\end{array}$ & $\mathbf{S}^{*}$ & $\begin{array}{c}\text { Ea } \\
(\mathbf{K J} / \mathbf{m o l}\end{array}$ \\
\hline \hline \multirow{3}{*}{ RS } & 301 & 26.6 & -88.40 & -23.00 & 88.17 & -13.88 \\
\cline { 2 - 7 } & 313 & 27.6 & - & - & - & - \\
\cline { 2 - 7 } & 323 & 28.5 & - & - & - & - \\
\hline \multirow{3}{*}{ MRS } & 301 & -30.1 & 100.27 & 36.38 & $1.86 \times 10^{-4}$ & 20.30 \\
\cline { 2 - 7 } & 313 & -31.3 & - & - & - & - \\
\hline
\end{tabular}

\section{REFERENCES}

[1] Ihsanullah, Aamir Abbas, Adnan M. Al-Amer, Tahar Laoui, Mohammed J. Al-Marri,Mustafa S. Nasser, Majeda Khraisheh, Muataz Ali Atieh; Separation and Purification Technology, 2016, 157, 141-161.

[2] Yunhai Wu, Yiang Fan, Meili Zhang, Zhu Ming, Shengxin Yang, Aynigar Arkin, Peng Fang; Biochemical Engineering Journal, Part A, 15 January 2016,105, 27-35

[3] Jong-Hwan Park, Yong Sik Ok, Seong-Heon Kim, Ju-Sik Cho, Jong-Soo HeoRonald D. Delaune, Dong-Cheol Seo;ChemosphereVolume , January 2016,142,77-83

[4] Upendra Kumar, Manas Bandyopadhyay; Bioresource Technology,2006,97, 104-109.

[5] Alireza Bazargan, Tesfalet Gebreegziabher, Chi-Wai Hui,Gordon McKay; biomass and bioenergy in press, 2014,1 8.

[6] A.K. Mohanty, M.A. Khan, G. Hinrichsen; Compos Sci Technol, 2000, 60, pp. 1115-1124.

[7] J. George, M.S. Sreekala, S. Thomas; Polymer Eng Sci, 2001, 41 (9), pp. 1471-1556.

[8] M.S. Sreekala, S. Thomas; Compos Sci Technol, 2003, 63, pp. 861-869.

[9] S. Wong, R. Shanks, A. Hodzic;Compos Sci Technol, 2004, 64, pp. 1321-1330.

[10] M.S. Sreekala, S. Thomas; Compos Sci Technol, 2003, 63, pp. 861-869.

[11] J.-T. Trejo-O'Reil, J.-Y. Cavaille; Cellulose, 1997, 4, pp. 305-320. 
[12] S. Yoshida, Y. Ohnishi, K. Kitaishi; The chemical forms, mobility and deposition of silicon in rice plant; Soil Sci Plant Nutr (Tokyo), 1962, 8 (15).

[13] Hengpeng Ye, Qing Zhu, Dongyun Du; Bioresource Technology, 2010,101, 5175-5179.

[14] Yuan Feng, Ji-Lai Gong, Guang-Ming Zeng, Qiu-Ya Niu, Hui-Ying Zhang, Cheng-Gang Niu, Jiu-Hua Deng, Ming Yan; Chem. Eng. J., 2010, 162, 487-494.

[15] D. Harikishore Kumar Reddy, K. Seshaiah, A.V.R. Reddy, S.M. Lee; Carbohydrate Polymers, 2012, 88, $1077-1086$.

[16] Ho, Y.S., Wase, D.A.J., Forster, C.F.;Water Res., 1995, 29,1327-1332.

[17] Yunhai Wu, Yiang Fan, Meili Zhang, Zhu Ming, Shengxin Yang, Aynigar Arkin, Peng Fang; Biochemical Engineering Journal, 2016, 105, 27-35.

[18] L. Largitte, T. Brudey, T. Tant, P. Couespel Dumesnil, P. Lodewyckx; Microporous and Mesoporous Materials, 2016, 219, 265-275.

[19] Congcong S., C. Chen, T. Wen, Z. Zhao, X. Wang, A. Xu; J.Colloid and Interf. Sci., 2015, 456, pp. 7-14.

[20] Lichun F., C. Shuang, F. Liu, A. Li, Y. Li, Y. Zhou, H. Song; J.Hazard. Mater., 2014, 272, pp. 102-111.

[21] S.A. Nabi, Mohammad Shahadat, Rani Bushra, A.H. Shalla, A. Azam;Colloids and Surfaces B: Biointerfaces, 2011, 87, 122-128.

[22] Asif A. K., S. Shaheen; Solid State Sciences, 2013, 16,158-167.

[23] Freundlich, H., J. Am.; Chem. Soc., 1918, 40, 1361-1403.

[24] Yanping Zhu, Naiyun Gao*, Qiongfang Wang, Xingya Wei; Colloids and Surfaces A: Physicochem. Eng. Aspects, 2015, 468, 114-121.

[25]Langmuir I.; J. Am. Chem. Soc.,1918, 40, 1361-403.

[26] Mary Jenish Barnabas, Surendran Parambadath, Aneesh Mathew, Sung Soo Park, AjayanVinu, Chang-Sik Ha; Journal of Solid State Chemistry, 2016, 233, 133-142.

[27]Temkin I.M., V. Pyzhev; Acta Physiochem. SSR, 1940, 12, pp. 217-222.

[28] Guiyin Zhou, Jinming Luo, Chengbin Liu, Lin Chu, Jianhong Ma, Yanhong Tang, Zebing Zeng, Shenglian Luo; Water Research, 2016, 89, 151-160.

[29] Dubinin, M.M., L.V. Radushkevich;Chem. Zentr, 1947, 1, pp. 875-889.

[30] Hong-Tao Fan, Wen Sun, Bing Jiang, Qing-Jie Wang, Da-Wu Li, Cong-Cong Huang, Kang-Jun Wang, Zhi-Gang Zhang, Wen-Xiu Li'; Chemical Engineering Journal, 2016, 286, 128-138.

[31] Priyabrata P., F. Banat; J. Natural Gas Scie. Eng., 2014, 18, 227-236.

[32] Lagergren S.; Handlingar, 1898, 24 (4) , pp. 1-39.

[33] Zhuhong Ding a,c, Xin Hub,c, Yongshan Wand, Shengsen Wang c, Bin Gao; Journal of Industrial and Engineering Chemistry, 2016, 33, 239-245.

[34] Ho Y.S., D.A. John Wase, C.F. Forster; Water Res.,1995, 29, 1327-1332.

[35] Kun-Yi Andrew Lin, Yu-Ting Liu, Shen-Yi Chen; Journal of Colloid and Interface Science, 2016, 461, $79-87$.

[36] Dilip Kumar Mondal a, Barun Kumar Nandi b, M.K. Purkait; Journal of Environmental Chemical Engineering, 2013, 1, 891-898.

[37] Özacar M. and I.A. Sengil; Process Biochem.,2005, 40, 565-572.

[38] Moaaz K. Seliem, Sridhar Komarneni, Mostafa R. Abu Khadra; Microporous and Mesoporous Materials, 2016, 224, 51-57.

[39] Malihe F., M.Beheshti, H. Sabzyan; J. Molecular Liquids, 2015, 211, 1060-1073.

[40] Jingjing W., Z. Lia; J Hazard. Mater., 2015, 300, 18-28.

[41] Yu, K., Gu, C., Boyd, S.A., et al.; Environ. Sci. Technol., 2012, 46, 8969-8975.

[42] Yanping Z., N. Gao, Q. Wang, X. We; Colloids and Surfaces A: Physicochem. Eng. Aspects, 2015, 468, $114-121$.

[43] Qiong L., J.Yu, F. Zhou, X. Jiang; Colloids and Surfaces A: Physicochem. Eng. Aspects, 2015, 482, $306-314$.

[44]Mehmet, U.; Microporous and Mesoporous Materials, 2009, 119, 276-283.

[45] Sushanta, D., Maity, A., Pillay, K., J. Environ. Chem. Engineering, 2014, 2, 260-272.

[46] Singh, B., Das, S. K.;Colloids and Surf. B: Biointer., 2013, 107,97-106. 